\title{
Differential Response Of The Ionosphere To Great Geomagnetic Storms During Solar Cycles 19-23
}

\author{
Junmi Gogoi ${ }^{1}$, Kalyan Bhuyan ${ }^{2}$ \\ Department of Physics ${ }^{1,2}$, Dibrugarh University ${ }^{1,2}$, Dibrugarh, Assam-786004, India \\ Email: saikiajunmigogoi@gmail.com ${ }^{1}$,kalyanbhuyan@gmail.com ${ }^{2}$
}

\begin{abstract}
The present study is aimed at discerning the ionospheric response to great geomagnetic storms (GGS) (Dst $\leq-200 \mathrm{nT}$ ) during solar cycles 19-23 along with their dependence on solar activity. The statistical analysis of the effect of geomagnetic storms on the F2 layer has been performed here by calculating the normalized deviation $\Delta$ foF2 of the critical frequency of F2 layer (foF2) in four ionosonde stations [Townsville (TV51R) $19.7^{\circ} \mathrm{S}, 146.9^{\circ} \mathrm{E}$; Canberra $(\mathrm{CB} 53 \mathrm{~N}) 35.3^{\circ} \mathrm{S}, 149.1^{\circ} \mathrm{E}$; Ahmedabad (AH223) $23^{\circ} \mathrm{N}, 72.6^{\circ} \mathrm{E}$; Juliusruh (JR055) $\left.54.6^{\circ} \mathrm{N}, 13.4^{\circ} \mathrm{E}\right]$ to perceive certain typical characteristics. Depending on the coordinates, local time of geomagnetic storm onset and some other parameters associated with the storm, the ionosphere over different ionosonde locations may respond quite differently to the same storm. The association of various solar-wind parameters such as $B_{Z}$ (southward interplanetary magnetic field), $B_{T}$ (tangential magnetic field), $V$ (plasma flow speed), $\rho$ (plasma proton density), $\Theta_{c}$ (clock angle) etc., with the Dst index has also been investigated. The correlation coefficients $r$ for the combinations of some of those parameters forming coupling functions for solar wind-magnetospheric interaction, with Dst minimum concerning those great geomagnetic storms are found to be satisfactorily good. The coupling function $\mathrm{V}^{4 / 3} \mathrm{~B}_{\mathrm{T}}^{2 / 3}$ shows a very good correlation with Dst minimum indicating that their coupling has a noticeable effect on the ionosphere. We have also found that more than $62 \%$ of the selected great storms occurred when the Interplanetary Magnetic field (IMF) was directed southward.
\end{abstract}

Index Terms- foF2; great geomagnetic storms; positive-negative phases of storms; solar parameters; Dst index.

\section{INTRODUCTION}

The earth and its nearer surroundings are affected by space weather. The sun is the main driver of space weather phenomena that erupts coronal mass ejections (CMEs), corotating interaction regions (CIRs) and solar flares. Enhanced solar wind and magnetosphere energy coupling affected by the magnetic reconnection process gives rise to geomagnetic storms and cause disturbances in the earth's magnetosphere [Dungey, 1961 ${ }^{1}$; Sugiura, 1964'; Gonzalez et al 1994³]. Geomagnetic storms remain to be a complex but an important weather issue since early days. It has been recognized as the extreme form of space weather disturbances which has not only its impact on the upper and middle atmosphere but also on the troposphere. The Dst index is a parameter which has been used to keep surveillance on the geomagnetic storms [Kamide et al. 1998 Using the Dst Index, storms can be categorized in to, namely- weak storms (Dst $>-50 \mathrm{nT}$ ), moderate storms $(-100 \mathrm{nT} \leq \mathrm{Dst} \leq-50 \mathrm{nT})$, intense storms ($200 \mathrm{nT} \leq$ Dst $\leq-100 \mathrm{nT}$ ) and great storms (Dst $\leq$ $-200 \mathrm{nT}$ ).

The intense geomagnetic storms can be induced by interplanetary coronal mass ejections (ICMEs) or a CIR [Goseling et al. $1991^{6}$, Tsurutani \& Gonzalez $1997^{7}$, Richardson et al. $2002^{8}$ and Zhang et al. $2007^{9}$ ]. While on the other hand, a GGS, which is meant to be the major sun-earth connection event, is caused by CMEs [Zhang et al. $2007^{9}$ and Echer et al. $2008^{10}$ ]. Intense and GGS are different from each other by not only in numbers but also by their physical meaning during a solar cycle.

After the discovery of geomagnetic storms, their terrestrial effects remains an attention-grabbing topic of the upper atmospheric physics and a lot of research work has been carried out on this topic disclosing various fascinating and sometimes some conflicting facts. Many aspects of this phenomenon are still not understood completely as there is a series of rapid and dramatic changes that take place in the ionosphere-magnetosphere due to the involvement of various causative mechanisms. So, an attempt has been carried out to understand the dynamics of solar wind-magnetosphere coupling process, to see what important facts are involved behind this phenomenon and how much they are important to create the event. As we are focusing mainly on the ionospheric effects of GGS (Dst $\leq-200 \mathrm{nT}$ ) so we need to know the causes of this phenomenon.

There are various ionospheric parameters that could be examined, but the one that has received a great deal of attention is the critical frequency of F2 layer (foF2). The variation of foF2 with reference to geomagnetic storms provides some important indications to this mechanism. The foF2 is related to the F2 peak electron density $\mathrm{NmF} 2$ by the equation given below:

$$
\mathrm{NmF} 2=1.24(\mathrm{foF} 2)^{2} \times 10^{10} \mathrm{el} . \mathrm{m}^{-3}
$$


International Journal of Research in Advent Technology, Vol.7, No.3, March 2019 E-ISSN: 2321-9637

\section{Available online at www.ijrat.org}

There are various factors which determine the ionospheric plasma density. These factors include solar photoionization, wind circulation, neutral composition etc., during magnetically quiet days, which successively causes disturbances in the F2 region plasma parameters. The electron density can either increase (positive phase) or decrease (negative phase) during ionospheric storms.

The morphology of positive and negative phases of ionospheric storms has been investigated by many authors. The longitudinal foF2 variability over equatorial and low latitude region was studied by Akala et al. (2011) ${ }^{11}$ and latitudinal variability was studied by Rashmi Patowary et al. (2013) ${ }^{12}$. Kane $(2005)^{13}$ has concluded that the negative storm effects seem to be more pronounced than that of positive storm effects while studying the foF2 anomalies during three very intense geomagnetic storms. The study did not reveal any reliable pattern of such anomalies in foF2 in individual storms.

\section{DATA AND METHODOLOGY}

This paper deals with the statistical analysis of GGS occurring from 1957 to 2006 which includes 5 solar cycles viz. 19, 20, 21, 22 and 23. Based on the availability of data during the period of these solar cycles, we have found a total of 65 GGS according to intensity. These storms are classified into three seasonal groups: summer, winter and equinoctial storms, referring to the seasons in the northern hemisphere. We mainly focus on foF2 variations during these GGS at 4 ionosonde stations - one in the European sector, one in the Asian sector and two in the Australian sector. The geographical locations of the chosen stations are given in Table 1. The paucity of data at most of the stations restricted the choice of the ionosonde stations. The data used in this analysis consists of the hourly values of Dst index and hourly values of foF 2 data for respective stations. To study the ionospheric response to a particular geomagnetic activity, one of the most suitable way is to find the normalized deviations of the foF2 i.e. $\Delta$ foF2 [Rashmi Patowary et al.(2013) ${ }^{12}$ ]

$$
\Delta \mathrm{foF} 2=\mathrm{foF} 2-\mathrm{foF} 2_{\text {mean }}
$$

The mean value of foF2 (foF 2 mean) for each hour is calculated from the four quiet days before and after the storm ( \pm 2 days from the storm) which is considered to be a reference for each hour. The normalized deviation of the foF2 is used instead of the critical frequency itself as it provides a first order correction for the variations so that the influences of geomagnetic storms are better recognized. Simultaneous plots for $\Delta$ foF 2 and Dst for each of the storms with respect to time have been obtained. Along with it the time of storm commencement (SC) and Dst minimum value is being noted here. To evaluate the influence of storms on various locations we have examined the universal time (UT) variations of the Dst index.

To study the quantitative correlation between the solar wind parameters and storm strength, the following parameters $-\mathrm{B}_{\mathrm{Z}}$ (southward interplanetary magnetic field), $\mathrm{B}_{\mathrm{T}}$ (tangential magnetic field), $\mathrm{V}$ (plasma flow speed), $\rho$ (plasma proton density), $\Theta_{c}$ (clock angle), etc. with the Dst index for the corresponding storms have also been investigated. Besides, the correlations of their coupling functions such as $\rho \mathrm{V}, \rho \mathrm{V}^{2} / 2, \mathrm{VB}_{\mathrm{Z}}, \mathrm{V}^{4 / 3} \mathrm{~B}_{\mathrm{T}}{ }^{2 / 3}, \mathrm{~B}_{\mathrm{T}}\left[\sin ^{4}\left(\Theta_{\mathrm{c}} / 2\right)\right]$, $\mathrm{VB}_{\mathrm{T}}\left[\sin ^{4}\left(\Theta_{\mathrm{c}} / 2\right], \quad \mathrm{VB}_{\mathrm{T}}^{2}\left[\sin ^{4}\left(\Theta_{\mathrm{c}} / 2\right)\right], \quad \mathrm{VB}_{\mathrm{T}}\left[\sin ^{2}\left(\Theta_{\mathrm{c}} / 2\right)\right]\right.$ along with solar-flux (F10.7) and sunspot number ( R ) has also been checked with regards to Dst minimum.

\section{RESULT AND DISCUSSION}

\subsection{Diurnal, Seasonal and Spatial Variations of storms}

During geomagnetic storms, the variations in foF2, given by $\Delta$ foF 2 , have average daily patterns in accordance with seasons and the location of the stations. However predictions based on general pattern could be rather inadequate. The seasonal classification of storms, i.e., summer, winter and equinoctial storms are in reference to the seasons in the northern hemisphere. So, when we analyse a storm in summer at Juliusruh and Ahmedabad, it is winter for Townsville and Canberra.

Kane $(2005)^{13}$, emphasized that the thermospheric composition, temperature and changes in the circulation affect the electron concentration in the F2 region. The spatial distribution of the negative and the positive phases during different seasons is determined by a variance between the storm-induced circulation and the regular pattern. The storms under investigation show following features:

3.1.1. Negative phase

It has been noticed that the intensity of $\Delta$ foF2 is prominently depicting negative phase for most of the storms. The negative effects with a small time lag indicate the presence of an equatorward drift during the storm from auroral latitudes to middle latitudes. The reason behind this maybe the fact that the velocity of the negative phase equatorward "drift" is, according to various estimates, about $50-300 \mathrm{~ms}^{-1}$ [Danilov and Belik, $1991^{14}$ ] and hence it seems to appear almost 
International Journal of Research in Advent Technology, Vol.7, No.3, March 2019

E-ISSN: 2321-9637

Available online at www.ijrat.org

Table 1. List of ionospheric stations used for measuring foF2

\begin{tabular}{|l|l|l|l|l|}
\hline Name of Stations & Code & Latitude (degrees) & Longitude (degrees) & Local time (hrs) \\
\hline Juliusruh & JR055 & $54.6^{\circ}$ & $13.4^{\circ}$ & UT+2 \\
\hline Ahmedabad & AH223 & $23^{\circ}$ & $72.6^{\circ}$ & UT +5.30 \\
\hline Townsville & TV51R & $-19.7^{\circ}$ & $146.9^{\circ}$ & UT +9.44 \\
\hline Canberra & CB53N & $-35.3^{\circ}$ & $149.1^{\circ}$ & UT +9.56 \\
\hline
\end{tabular}

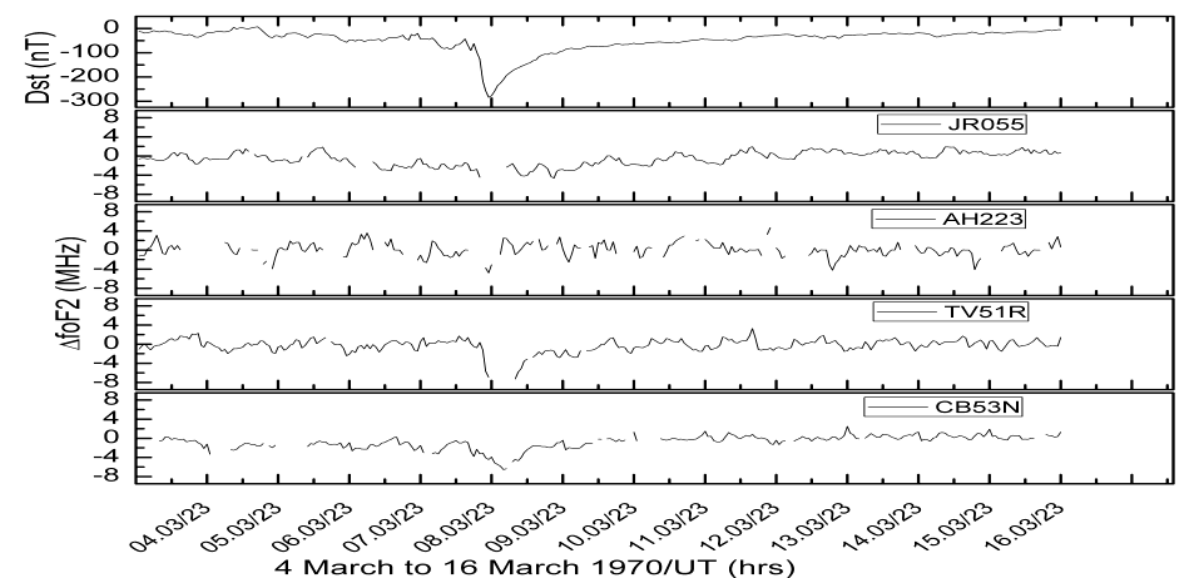

Fig.1. Geomagnetic storm occurring from 4 March to 16 March 1970 showing negative phase of $\Delta$ foF2.

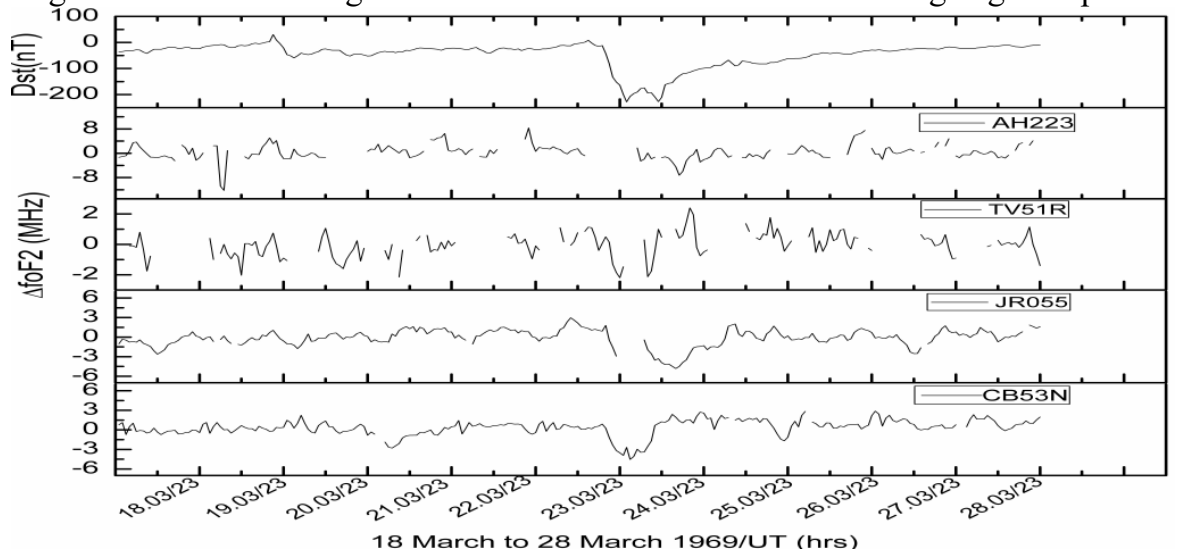

Fig.2. Geomagnetic storm occurring from 18 March to 28 March 1969 showing negative phase of $\Delta$ foF2

simultaneously at all the latitudes. Sometimes, for stationary daytime conditions without any vertical drifts, the electron concentration is found to be directly proportional to the $[\mathrm{O}] /\left[\mathrm{N}_{2}\right]$ ratio [Rishbeth and Barron, $1960^{15}$ ].

It has been found that about $48 \%$ of the selected storms occurred in the equinox. Figure 1 shows an equinoctial storm that occurred on 8 March 1970 with the corresponding $\Delta$ foF2 variation in the chosen stations. An enhanced negative effect is observed during the night time in Townsville with a time lag of 2 hours compared to Canberra in the Australian sector, indicating that night time thermospheric circulation which is directed equatorward enhances the short-time equatorward drift. As the velocity of the equatorward drift is very high so the negative effect seems to have appeared simultaneously, whereas in the northern hemisphere, i.e. in Juliusruh the $\Delta$ foF 2 shows a very small negative phase effect. This may be due to the reason that if during magnetic disturbances the thermospheric dynamical regime stayed unchanged, then the $[\mathrm{O}] /\left[\mathrm{N}_{2}\right]$ ratio gets depleted and hence the electron concentration and thus foF2 would be controlled by the high latitude ionosphere. For Ahmedabad, the storm commencement time is in the late afternoon and the negative deviation is also found to be very less. This indicates that the thermospheric circulation is directed poleward during the daytime, which neutralizes the storm time equatorward circulation.

Figure 2 is an example of a storm which occurred in winter northern hemisphere depicting very 


\section{Available online at www.ijrat.org}

pronounced negative deviation in all the stations. The storm commencement takes place on 18 March in Canberra during night time with a time lag of nearly 3 hours in Townsville signifying the equator-ward drift. In the northern hemisphere during summer, the thermospheric circulation is found to be equator wards and thus it elevates the equatorward drift of storm time circulation. And also in summer, the poleward background circulation is weaker than that of winter. At most of the time, it is found to be equatorward and so it coincides with the storm-induced circulation. It makes the condition suitable for penetration of the air with a depleted $[\mathrm{O}] /\left[\mathrm{N}_{2}\right]$ ratio to mid-latitudes. As such, during the summer season, the negative deviation in foF2 can be observed both in the day and night time at the mid latitudes. So, maybe due to this reason the negative deviation of Townsville is more prominent than that of Canberra in this storm. On the other hand, Juliusruh which is located at high latitude, the storm commencement takes place on 19 March during the daytime showing a clear negative deviation, since in winter during the daytime, the thermospheric circulation is found to be directed poleward neutralizing the storm-time equatorward circulation.

\subsubsection{Positive phase}

Positive storms are very rarely observed in almost all of the stations as compared to the occurrence of negative storms. The features of the positive storms are quite different from that of negative ones. Some of the probable sources of this mechanism are- (a) uplifting of the F2-layer due to vertical drift, (b) plasma fluxes from the plasmasphere and (c) downwelling of the gas as a consequence of the storminduced thermospheric circulation [Danilov and Belik, $1991^{14}$; Prölss, $1995^{16}$ ]. Figure 3 is an example of two combined storms depicting two clear positive deviations at all the stations selected over here, which occurred from 12 September 1963 to 2 October 1963. Normally, positive ionospheric storms are associated with magnetic activity beginning in the local daytime. In Juliusruh, two typical positive peaks are seen during the daytime, which occurs several hours after the commencement of storm. Usually, the storminduced circulation increases the upward vertical drift of plasma in the F2 layer and results in elevating the layer and then it leads to increase in electron concentration. At the middle latitudes it is the most usual cause of the positive phase. But while moving from the higher latitude to the equator in both the

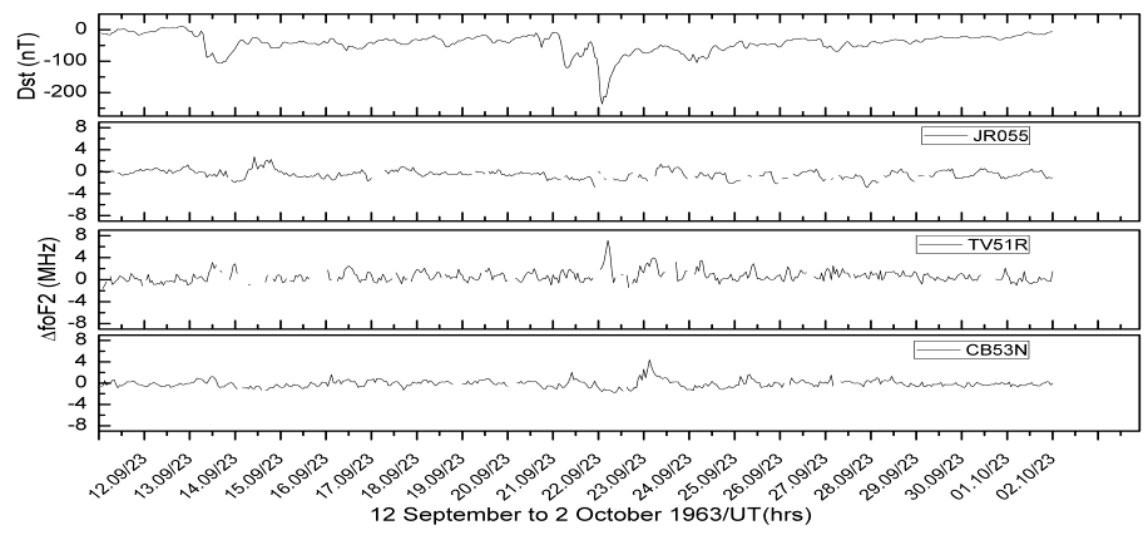

Fig.3. Geomagnetic storm occurring from 12 September to 2 October, 1963 showing positive phase of $\Delta$ foF2.

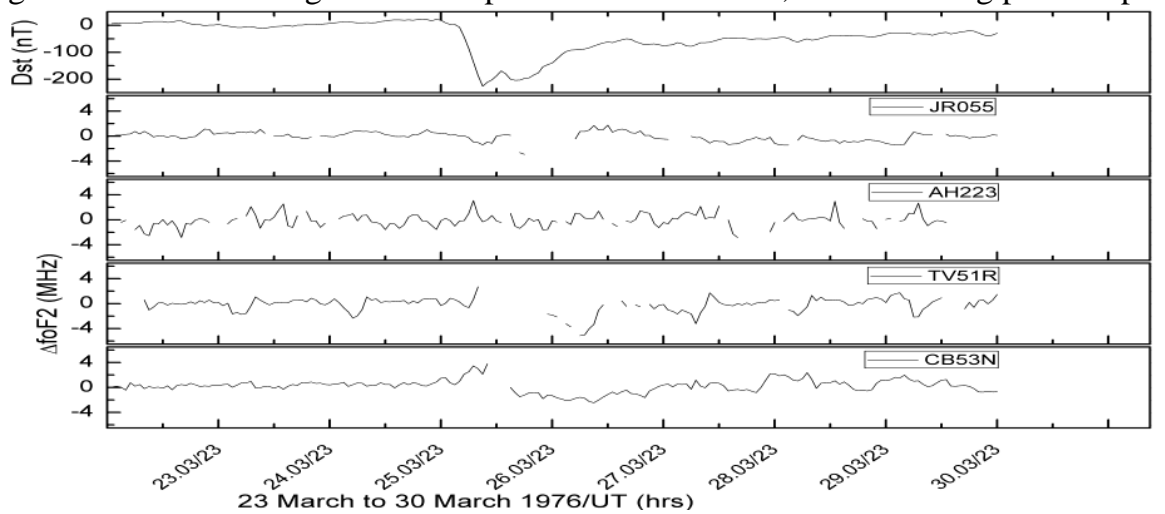

Fig.4. Geomagnetic storm occurring from 23 March to 30 March 1976 showing both positive and negative phase of $\Delta \mathrm{foF} 2$

hemispheres, the positive $\Delta$ foF2 get flattened lowered. In Townsville and Canberra, the storm generally. And it could possibly be due to the storm- commencement takes place during the daytime but induced circulation which lowers down the gas with reduced $[\mathrm{O}] /\left[\mathrm{N}_{2}\right]$ ratio, as a result of which the electron concentration in F2 peak maybe getting few hours earlier than Juliusruh in the northern hemisphere. They show very sharp positive peaks and it is attributed to seasonal effects, as it is known that 


\section{Available online at www.ijrat.org}

the positive phase often occurs in the winter hemisphere, while negative storm is more of a summer hemisphere "feature" [e.g., Prölss, 1995 Goncharenko et al., 2007 ${ }^{17}$; Danilov, 2013 ${ }^{18}$ ]. Sometimes, the injection of solar wind energy to the polar upper atmosphere launches so-called travelling atmospheric disturbance (TAD) causing daytime positive storm effects of short duration by an uplifting of the F2 layer at mid latitudes.

3.1.3. Positive and Negative storms

Combination of both positive and negative phases has been observed mainly during the summer, a few in equinox and rarely in winter storms. Sometimes in summer, it has been observed that the quiet time particles and storm-induced circulating particles get overlapped and hence the upward vertical drift increases creating the positive phase. On the other hand, the gas with the depleted $[\mathrm{O}] /\left[\mathrm{N}_{2}\right]$ ratio is carried by the storm-induced circulation causing a lessening of the electron concentration in the F2 layer and as such creates the negative phase [Adeniyi, $1986^{19}$; Turunen and Rao, $1980^{20}$ ]. Thus, in summer, there is a probability of finding a storm with the combination of both positive and negative phases. Along with it another most common characteristics found is that, the magnitude of $\Delta$ foF2 gets trimmed down while moving successively to the lower latitudes. Figure 4 is an example of storms showing both positive and negative phases during the time of storm that occurs from 23 March to 30 March 1976 in the equinoctial period. In the northern hemisphere, this effect is found to diminish while moving from Juliusruh to Ahmedabad. And in the southern hemisphere, both Townsville and Canberra show a clear picture of such storms with not much variance in between them.

3.1.4. Variation in phase due to location as well due to the intensity of storm

Ionospheric foF2 variation is dependent on a number of mechanisms, the magnitude of negative or positive $\Delta$ foF2 varied a lot from storm to storm and sometimes even within the same storm. It has been noticed that, due to the variation of intensity of the storm and of course due to variation in the location of the station, some storms show anomalous nature. They do not show any systematic latitude difference. If for one station it shows positive phase while for the other it shows negative phase and sometimes the combination of both the phases. Example of such a storm is shown in figure 5. An enhanced negative deviation has been

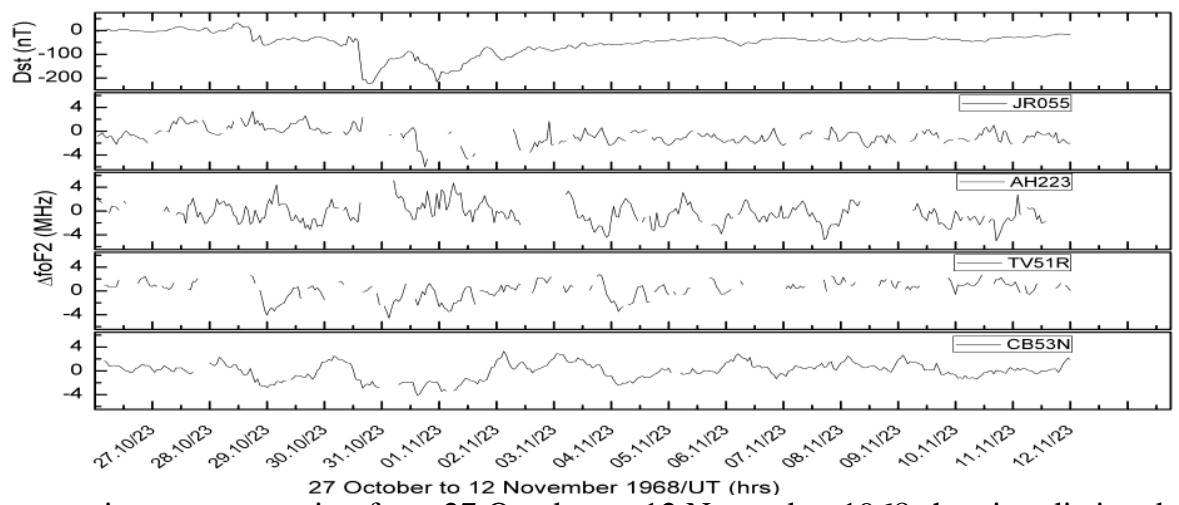

Fig.5. Geomagnetic storm occurring from 27 October to 12 November 1968 showing distinct behavior i.e. JR055, TV51R \& CB53N shows negative phase, AH223 shows enhanced positive phase of $\Delta$ foF 2

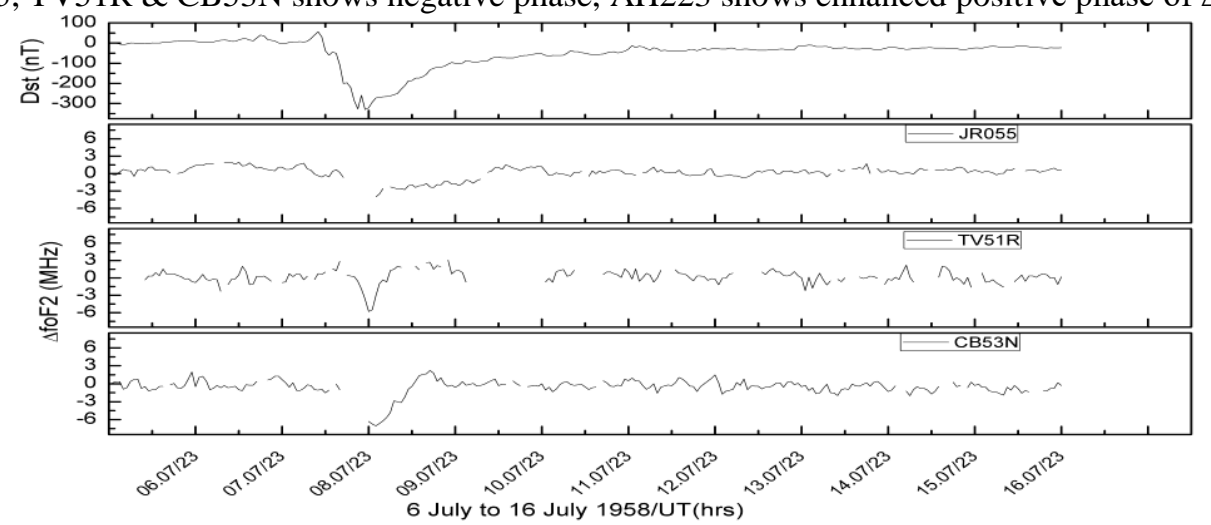

Fig.6. Geomagnetic storm occurring from 6 July to 16 July 1958 showing positive phase before storm commencement.

noted in Canberra, Townsville and Juliusruh during the storm that occurs from 27 October to 12 November 1968. This is again because of the fact that in both the hemispheres at high latitudes, the heating of thermosphere during geomagnetic disturbances affects changes in the thermospheric composition and subsequently causes the negative phase. Moreover, during the daytime in winter the thermospheric circulation is poleward and hence it neutralizes the storm-time equatorward flow. Thus, the region of the 


\section{Available online at www.ijrat.org}

negative phase expansion remains curbed to high latitudes, while an enhanced positive phase has been noted in Ahmedabad which indicates that the F2-layer plasma is boosted up by the equatorward horizontal thermospheric circulation along the inclined field lines.

\subsubsection{Positive phase prior to storm commencement}

One of the most striking features of some storms is the sudden positive deviation, which occurs several hours before the commencement of Dst storm which was noted by Kane $\left(1973 a b^{21}, 1975^{22}, 2005^{13}\right)$, Rashmi Patowary et al. (2013) $)^{12}$, and Danilov and Belik $\left(1991^{14}, 2001^{23}\right)$. After this sudden positive deviation, most of the time Dst shows a strong negative deviation in the main phase. Such a clean picture of pre-storm deviation is shown in figure 6 (6 July to 16 July 1958) and figure 1(6 May to 16 May 1992). There may be several reasons behind this unusual behavior. Even in the quiet geomagnetic conditions also ionospheric parameters may vary [Forbes et al. $2000^{24}$ ]. This variation could be well thought-out as random or could be due to meteorological influences. Another important point is the geomagnetic effect, ionospheric parameters varies with increasing geomagnetic activity while moving from low latitude to higher one. Again Tsurutani et al. (2005) ${ }^{25}$ have investigated the global ionospheric effects of the storm on $28^{\text {th }}$ October 2003 and found $30 \%$ increment in TEC for about $\sim 3$ hours. The outcomes of this study leads to the conclusion that some positive pre-storm that occur during the tenure of $24 \mathrm{hrs}$ could be due to the enduring effects of the additional ionization caused by the strong solar flare effects. On the other hand, Rishbeth and Mendillo (2001) ${ }^{26}$ have reported that the maximum variability of the F2 layer is largely linked with geomagnetic activity and the rest to the meteorological origin. So, it may be possible that meteorological origin could also be a part of the causes of positive effects before the commencement of geomagnetic storm. But however, this tactics of forming sudden positive pre storm may not work sometimes, as there is still no any depleted $[\mathrm{O}] /\left[\mathrm{N}_{2}\right]$ or

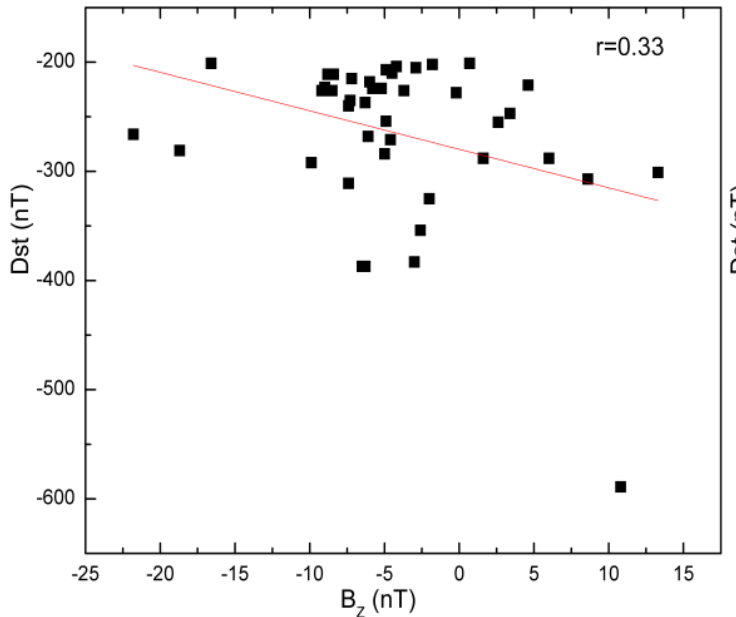

Fig.7(a). Plot of minimum Dst peak versus $B_{Z}$

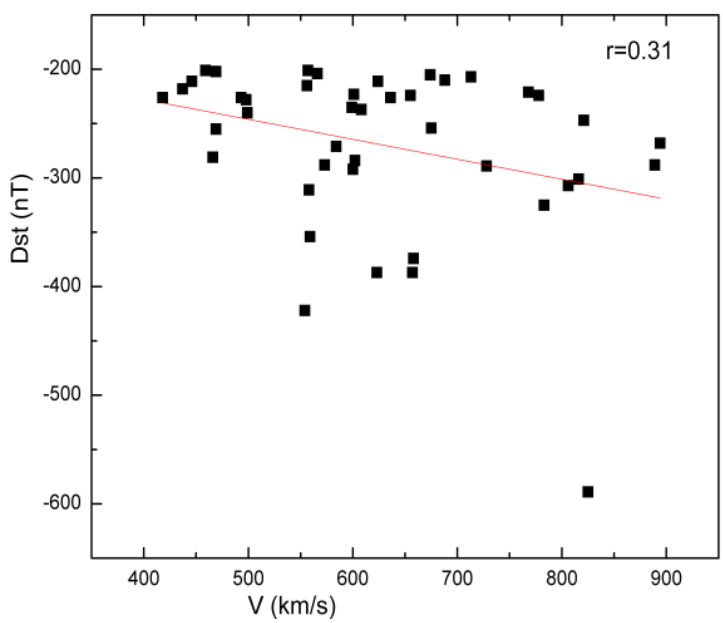

Fig.7(c). Plot of minimum Dst peak versus V

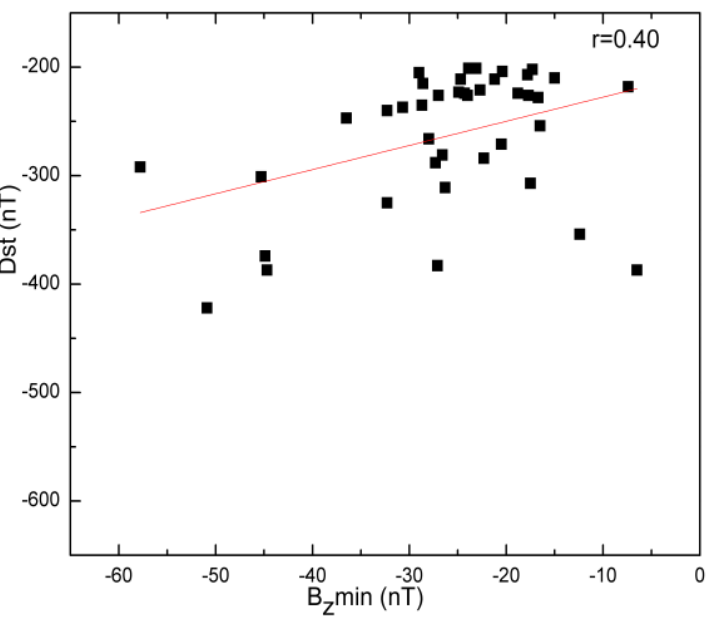

Fig.7(b). Plot of minimum Dst peak versus $B_{Z}$ min

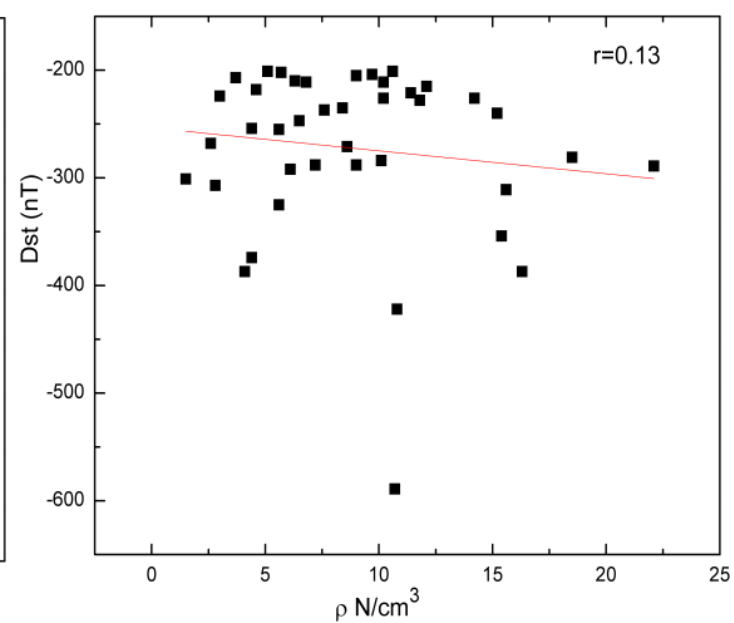

Fig.7(d). Plot of minimum Dst peak versus $\rho$ 


\section{Available online at www.ijrat.org}

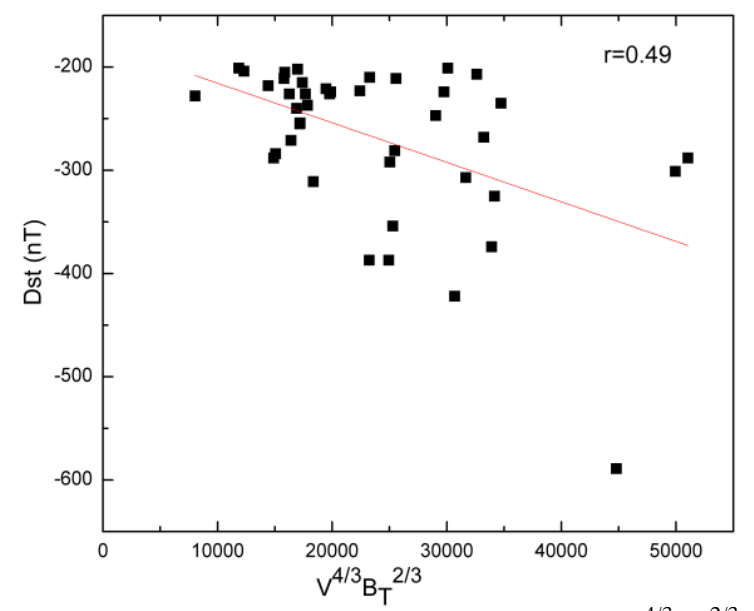

Fig.7(e). Plot of minimum Dst peak versus $\mathrm{V}^{4 / 3} \mathrm{~B}_{\mathrm{T}}{ }^{2 / 3}$

nor any storm-induced circulation. It could be the ramification of the soft particle participation that exudes from the slow moving solar energetic particles in the vicinity of day side cusp. The cusp is the only region that acts in response to the impending geomagnetic disturbances before any of the geomagnetic indices do: and a few hours before the Dst depletion occurs the cusp starts travelling towards the equator (Danilov and Belik, 1992 ${ }^{27}$ ). These are some of the known facts of positive phase prior to storm commencement.

\subsection{Coupling parameters for solar wind- magnetospheric interaction}

One of the most common and simplest techniques to determine the strength of the relationship between a dependent and independent variable is the method of linear regression. Regression lines give us useful information about the collected data. They show how one variable changes on average with another, and they can be used to find out what one variable is likely to be when we know the other. So, here by using this method we want to explore the extent of association between the Dst minimum and the solar-wind parameters along with their coupling functions by finding the correlation coefficient ( $\mathrm{r}$ ). The correlation coefficient between some of the parameters and their coupling functions with the Dst index is found to be good and this signifies the extent of solar windmagnetospheric interaction. The relationship of some parameters has been explained below:

\subsubsection{Parameter $\quad B_{Z} \quad$ (southward interplanetary magnetic field)}

The Dst peak and corresponding value of southward IMF $B_{Z}$ for 44 storms (Dst $\leq-200 \mathrm{nT}$ ) have been plotted in figure 7(a). The correlation coefficient is found to be $r=0.173205$. The result may be due to the fact that $\mathrm{B}_{\mathrm{Z}}$ has significant growth mainly during (or before) the initial phase of geomagnetic storm and not during the main phase which has been tested here. We have also found the correlation between Dst minimum and $\mathrm{B}_{\mathrm{Z}}$ minimum value. Here the correlation coefficient $(r=0.40)$ is found to be better than that of $\mathrm{B}_{\mathrm{Z}}$ 's corresponding to Dst minimum. The plot of Dst minimum and $B_{Z}$ minimum is shown in figure $7(b)$.

\subsubsection{Parameter V (plasma flow speed)}

The correlation of Dst peak with respect to plasma flow speed $\mathrm{V}$ is found to be $\mathrm{r}=0.308221$ for the storms and it has been shown in figure 7(c). According to Kane (2005), the intense geomagnetic storm occurs for velocity above $350 \mathrm{~km} \mathrm{~s}^{-1}$, and above this limit $\mathrm{V}$ cannot be related to Dst. For great geomagnetic storms, selected here, the velocity is found to vary within the range of $418-894 \mathrm{~km} \mathrm{~s}^{-1}$, but $\sim 56 \%$ storms occur within range $600-894 \mathrm{kms}^{-1}$. Maybe due to this reason, the correlation is found to be moderate. It has been reported by Ballatore $(2005)^{28}$ that there is a saturation effect of fast solar wind on geomagnetic storms so the Dst doesn't measure up with larger solar wind speeds.

\subsubsection{Parameter $\rho$ (plasma proton density)}

Figure 7(d) shows the plot of Dst peak versus the corresponding value of solar plasma proton density $\rho$. The correlation coefficient is found to be very low for the storms selected here. $\rho$ is found to be less than $30 \mathrm{n} / \mathrm{cc}$ for these selected great storms. About $57 \%$ of them are found to be below $10 \mathrm{n} / \mathrm{cc}$ and $43 \%$ of them are found to be in the range of $10 \mathrm{n} / \mathrm{cc}$ to $27 \mathrm{n} / \mathrm{cc}$. As the correlation is very poor, there is no any prominent relationship found between the Dst peak and solar plasma proton density. So, a conclusion may be drawn geomagnetic storms with greater intensity are not exigently interrelated with solar plasma proton density of higer values. It points to the fact that there is a high plausibility of the intensity of a geomagnetic storm being not determined by the increased density.

\subsubsection{Variations with other coupling parameters}

In order to describe the interaction of magnetosphere and ionosphere it is necessarily being important to check how the functional forms of coupling 


\section{E-ISSN: 2321-9637}

\section{Available online at www.ijrat.org}

parameters with respect to Dst minimum is correlating. Figure 7(e) shows the scatter plot between Dst peak and $\mathrm{V}^{4 / 3} \mathrm{~B}_{\mathrm{T}}{ }^{2 / 3}$. The correlation coefficient for these great geomagnetic storms is found to be $\mathrm{r}=0.489898$ which can be considered as averagely good. The correlation coefficients for other parameters are listed in Table 2

\section{CONCLUSION}

It has been noticed that the great geomagnetic storms are found to occur mostly in equinox than in summer and winter. Among all the 65 great geomagnetic storms it has been observed that $58.5 \%$ storms occurred during the equinoctial time, $21.5 \%$ storms are found to occur during summer and $20 \%$ storms are found to occur in winter. Figure 8 shows the count of great geomagnetic storms in terms of percentage that occurs seasonally. The negative effect is found to be more certain for all the storms observed, which is in support with Kane $(2005)^{13}$. The Ionosonde stations, Townsville and Ahmedabad show more positive effect compared to Canberra and Juliusruh, and this is because, $\Delta$ foF 2 gets gradually flattened due to the reduced $[\mathrm{O}] /\left[\mathrm{N}_{2}\right]$ ratio as we approach the equator. The occurrence of both positive and negative phases is found not only during winter (mainly) but also in equinox and summer. Another point to be noted is that, more than $62 \%$ of the selected great storms are found to occur when the IMF direction is southward.

Table 2. Correlation coefficients of various coupling parameters with Dst peak value.

\begin{tabular}{|l|l|}
\hline Solarwind parameters & Correlation Coefficient, $\mathbf{r}$ \\
\hline $\mathrm{B}_{\mathrm{Z}}$ & 0.173205 \\
\hline $\mathrm{B}_{\mathrm{Z}}$ minimum & 0.40 \\
\hline$\Theta_{\mathrm{c}}$ & 0.158114 \\
\hline $\mathrm{B}_{\mathrm{T}}$ & 0.2 \\
\hline$\rho$ & 0.016062 \\
\hline $\mathrm{V}$ & 0.308221 \\
\hline$\rho \mathrm{V}$ & 0.13784 \\
\hline$\rho \mathrm{V}^{2} / 2$ & 0.244949 \\
\hline $\mathrm{VB}$ & 0.212132 \\
\hline $\mathrm{V}_{\mathrm{Z}}^{4 / 3} \mathrm{~B}_{\mathrm{T}}^{2 / 3}$ & 0.489898 \\
\hline $\mathrm{B}_{\mathrm{T}}\left[\sin ^{4}\left(\Theta_{\mathrm{c}} / 2\right)\right]$ & 0.001732 \\
\hline $\mathrm{VB}_{\mathrm{T}}\left[\sin ^{4}\left(\Theta_{\mathrm{c}} / 2\right]\right.$ & 0.1 \\
\hline $\mathrm{VB}_{\mathrm{T}}^{2}\left[\sin ^{4}\left(\Theta_{\mathrm{c}} / 2\right)\right]$ & 0.07746 \\
\hline $\mathrm{VB} \mathrm{B}_{\mathrm{T}}\left[\sin ^{2}\left(\Theta_{\mathrm{c}} / 2\right)\right]$ & 0.189737 \\
\hline $\mathrm{F} 10.7(\operatorname{solarflux})$ & 0.360555 \\
\hline $\mathrm{R}\left(\operatorname{Sunspot}^{\mathrm{N} o .)}\right.$ & 0.254951 \\
\hline
\end{tabular}




\section{Available online at www.ijrat.org}

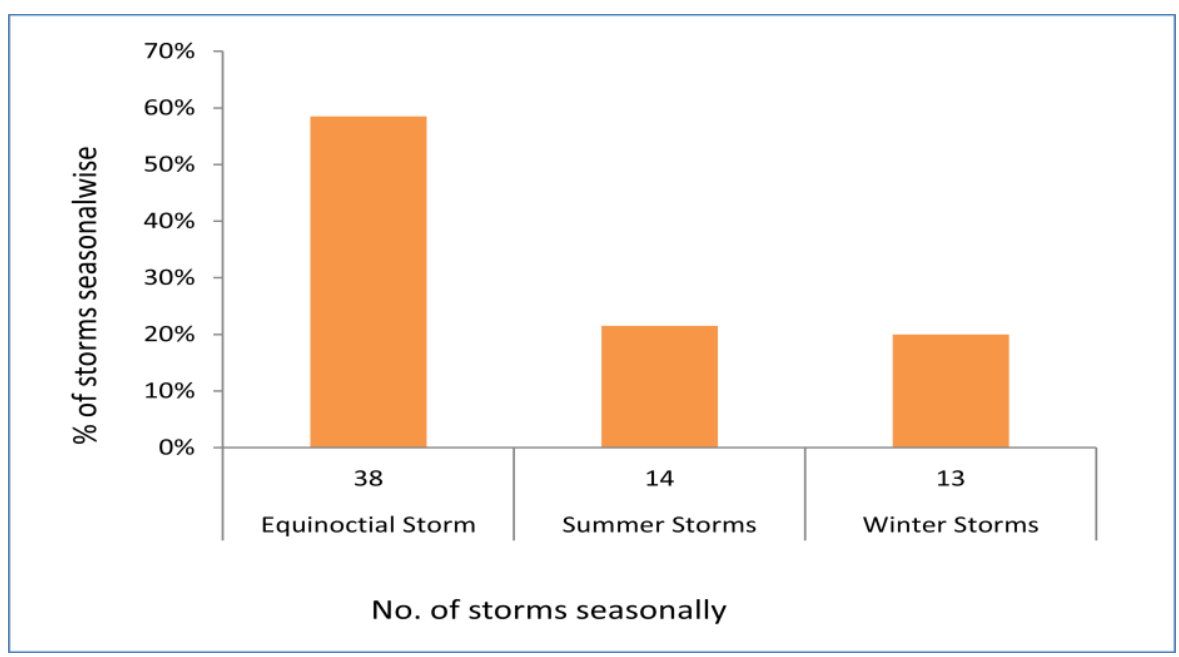

Fig.8. Count of great geomagnetic storms seasonally in terms of percentage.

This signifies that, as if, one of the main causes of great geomagnetic storms is the magnetic reconnection between the southward IMF and magnetopause fields, which is in support with Echer et al., $2008^{10}$. The correlation of Dst with the solar wind parameters are found to be moderate for the storms under investigation. The low correlation ( $\mathrm{r}=0.173205)$ between Dst and $\mathrm{B}_{\mathrm{Z}}$ can be associated with the time delay between their peaks, which was also pointed out by Rathore et al. $2011^{29}$. The correlation of Dst minimum and $\mathrm{B}_{\mathrm{Z}}$ minimum is found to be comparatively good i.e., $(\mathrm{r}=0.40)$. The coupling function $\mathrm{V}^{4 / 3} \mathrm{~B}_{\mathrm{T}}{ }^{2 / 3}$ shows a comparatively good correlation coefficient $(r=0.56)$ after the removal of two data points from the observation.

\section{ACKNOWLEDGEMENTS}

The author is grateful to World Data Centre (http://wdc.kugi.kyoto-u.ac.jp/dst_final), Kyoto, Japan for the Dst Index data and Space Physics Data Facility, NASA/Goddard Space Flight Center's OMNIWeb

(http://omniweb.gsfc.nasa.gov/form/dx1.html) for the hourly interplanetary, geomagnetic and solar wind parameters used in this work and finally thankful to UK Solar System Data Centre (https://www.ukssdc.ac.uk/wdcc1/ionosondes/secure/i ono_data.shtml) for the ionosonde data.

\section{REFERENCES}

[1] J. W. Dungey, Interplanetary magnetic field and the auroral zones, Phys Rev Lett (U.S), 6, pp 47-48, 1961.

[2] M. Sugiura, Hourly values of equatorial Dst for the IGY, in Annals of the International Geophysical Year, Elsevier (New York), vol. 35, pp 945-- 948,1964.

[3] W. D. Gonzalez, J. A. Joselyn, Y. Kamide, H. W. Kroehl, G. Rostoker, B. T. Tsurutani \& V. M. Vasyliunas, What is a geomagnetic storm?, J Geophys Res(USA), 99, 5771-5792, 1994.

[4] Y. Kamide, W. Baumjohann, I. A. Daglis, W. D. Gonzalez, M. Grande, J. A. Joselyn, R. L.
McPherron, J. L. Phillips, E.G.D. Reeves, G. Rostoker, A.S. Shanna, H.J. Singer, B.T. Tsurutani \& V.M. Vasyliunas, Current understanding of magnetic storms: Stormsubstorm relationships, J Geophys Res (USA), 103, 17,705 -- 17,728, 1998.

[5] I. A. Daglis, R. M. Thorne, W. Baumjohann \& S. Orsini, The terrestrial ring current: Origin, formation and decay, Rev Geophys (UK), 37(4), 407-438, 1999.

[6] J .T. Gosling, D. J. McComas, J. L. Phillips \& S $\mathrm{J}$ Bame, Geomagnetic activity associated with Earth passage of interplanetary shock disturbances and coronal mass ejections, J Geophys Res (USA), 96, 7831, 1991.

[7] B.T. Tsurutani \& W.D. Gonzalez, The interplanetary causes of magnetic storms: a review, Geophys Monogr Ser, edited by Tsurutani B T, Gonzalez W D, Kamide Y \& Arballo J K, AGU (Washington D C), 98, 7787, 1997.

[8] I.G. Richardson, H.V. Cane \& E.W. Cliver, Sources of geomagnetic activity during nearly three solar cycles (1972-2000), J Geophys Res (USA), 107(A8), 1187, 2002.

[9] J. Zhang, I.G. Richardson, D.F. Webb, N. Gopalswamy, E. Huttunen, J. C. Kasper, N. V. Nitta, W. Poomvises, B.J. Thompson, C-C Wu, S. Yashiro \& A.N. Zhukov, Solar and interplanetary sources of major geomagnetic storms (Dst $\leq-100$ nT) during 1996- 2005, J Geophys Res (USA), 112, A10102, 2007.

[10] E. Echer, W.D. Gonzalez, B.T. Tsurutani \& A. L.C. Gonzalez, Interplanetary conditions causing intense geomagnetic storms (Dst $\leq 100$ nT) during solar cycle 23 (1996-2006), J Geophys Res (USA), 113, (A5221), 2008.

[11] A.O. Akala, E.O. Somoye, A.B. Adeloye \& A. B. Rabiu, Ionospheric foF2 variability at equatorial and low latitudes during high, moderate and low solar activity, Indian J R Space Phys (India), 40, pp 124-129, 2011. 


\section{Available online at www.ijrat.org}

[12] R. Patowary, S.B. Singh \& K. Bhuyan, Latitudinal variation of F2-region response to geomagnetic disturbance, Adv Space Res (COSPAR publication), 52, pp 367-374, 2013.

[13] R. P. Kane, Ionospheric foF2 anomalies during some intense geomagnetic storms, Ann Geophys (Brazil), 23, pp 2487-2499, 2005.

[14] A.D. Danilov \& L.D. Belik, Thermosphereionosphere interaction in a period of ionospheric storms, Geomagn Aeron (Russia), 31, pp 157-167, 1991.

[15] H. Rishbeth \& D.W. Barron, Equilibrium electron distributions in the ionospheric F2layer. J Atmos Terr Phys (Northern Ireland), 18, 234-252, 1960.

[16] G.W. Prölss, Ionospheric F-region storms, in: Handbook of Atmospheric Electrodynamics, 2, edited by: Volland H, (CRC Press, Boca Raton), 195-248, 1995.

[17] L.P. Goncharenko, J.C. Foster, A.J. Coster, C. Huang, N. Aponte \& L.J. Paxton, Observations of a positive storm phase on September 10, 2005, J Atmos Sol Terr -Phys (UK), 69, 1253-1272, 2007.

[18] A.D. Danilov, Ionospheric F-region response to geomagnetic disturbances, Adv Space Res (UK), 52(3), 343-366, 2013.

[19] J.O. Adeniyi, Magnetic storm effect on the morphology of the equatorial F2 layer, J Atmos Sol Terr Phys (UK), 48, 695, 1986.

[20] T. Turunen \& M.N. Rao, Examples of the influence of strong magnetic storms on the equatorial $\mathrm{F}$ layer. J Atmos Sol Terr Phys (UK), 42, 323, 1980.

[21] R.P. Kane, Storm-time variations of F2, Ann de Geophys (US), 29, pp 25-42, 1973 a.

[22] R.P. Kane, Global evolution of the ionospheric electron content during some geomagnetic storms, J Atmos Terr Phys( Northern Ireland), 37, pp 601-611, 1975.

[23] A.D. Danilov, F-2 region response to geomagnetic disturbances, J Atmos SolarTerres Phys (UK), 63, 441-449, 2001.

[24] J. M. Forbes, S.E. Palo \& X. Zhang, Variability of the ionosphere, J Atmos Solar-Terr Phys (UK), 62, 685-693, 2000.

[25] B.T. Tsurutani, D.L. Judge, F.L. Guarnieri, P. Gangopadhyay, A.R. Jones, J. Nuttall, G.A. Zambon, L . Didkovsky, A.J. Mannucci, B. Iijima, R.R. Meier, T.J. Immel, T.N. Woods, S. Prasad, L. Floyd, J. Huba, S.C. Solomon, P. Straus \& R. Viereck, The 28 October 2003 extreme EUV solar flare and resultant extreme ionospheric effects: Comparison to other Halloween events and the Bastille Day event, Geophys Res Lett(US), 32, L03S09, 2005.

[26] H. Rishbeth \& M. Mendillo, Patterns of F2layer variability, J Atmos Solar-Terr Phys (UK), 63, 1661-1680, 2001.
[27] A.D. Danilov \& L.D. Belik, Thermospheric composition and the positive phase of an ionospheric storm, Advan Space Res (UK), 12 (10), pp 257-260, 1992.

[28] R.P. Kane, How good is the relationship of solar and interplanetary plasma parameters with geomagnetic storms?, J Geophys Res (USA), 110, A02213, 2005.

[29] P. Ballatore, Effects of fast and slow solar wind on the correlations between interplanetary medium and geomagnetic activity, J Geophys Res (USA), 107(A9), 1227, 2002. 